\title{
Myc and Ras collaborate in inducing accumulation of active Cyclin E/Cdk2 and E2F
}

\section{Gustavo Leone, James DeGregori, Rosalie Sears, Laszlo Jakoi \& Joseph R. Nevins}

Nature 387, 422-425 (1997)

Due to a production error in the film output process, essential information was lost from the gel images of Figs 3 and 4 in this Letter. The figures are reproduced here, with legends, and reprints including the corrected figures are available from the authors.

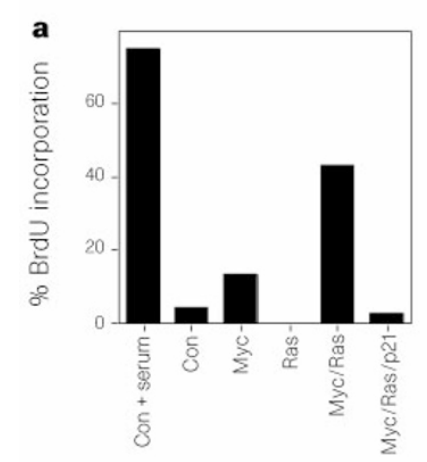

c

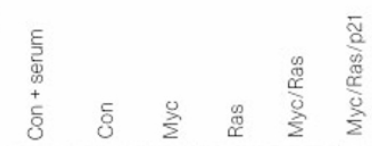

$-1-2=\begin{aligned} & \mathrm{Rb}-\mathrm{P} \\ & -\mathrm{Rb}\end{aligned}$

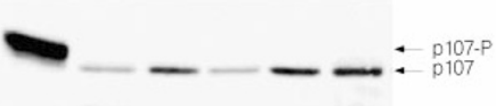

e

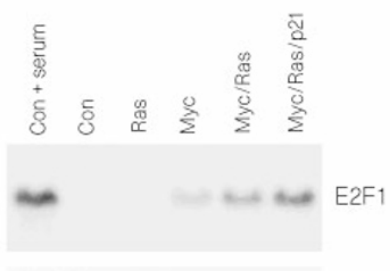

a

GAPDH

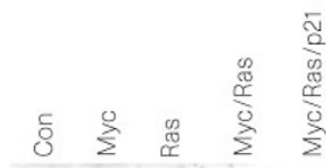

$-\infty$

p27 protein b

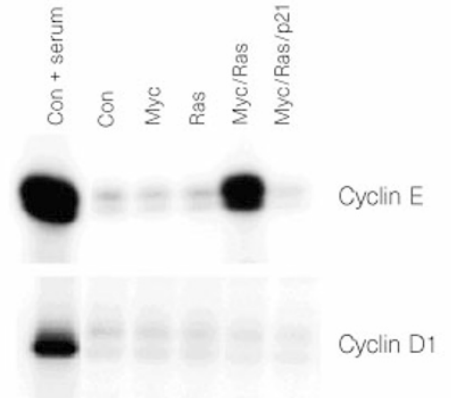

d
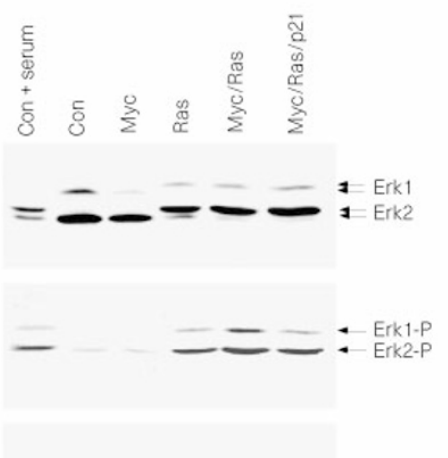

- Cdc25A

4 Figure 3 Ras and Myc collaborate to allow accumulation of G1 CDK activity and induction of $S$ phase. a, Quiescent REF52 cells were infected with the indicated viruses and BrdU was added after $12 \mathrm{~h}$ of infection. Cells were collected $30 \mathrm{~h}$ post-infection and $\mathrm{BrdU}$ detected by indirect immunofluorescence. Multiplicities of infection were: Ad-Myc (200); Ad-Ras61L (100); Adp21 (200); and Ad-Con (300). b, Expression of Ras and Myc leads to induction of cyclin E/Cdk2 but not cyclin D/Cdk4 activity. Cells treated as in a were collected $30 \mathrm{~h}$ post-infection, lysates were immunoprecipitated, and associated kinase activity was determined using histone $\mathrm{H} 1$ (top) and GST-Rb (bottom) as previously described ${ }^{27}$. Affinity-purified rabbit polyclonal antibodies anti-cyclin E (SC-481) and anti-cyclin D1 (SC-450) were purchased from Santa Cruz Biotechnology. c, Expression of Ras and Myc does not result in Rb or p107 phosphorylation. Cells treated as in a were collected $30 \mathrm{~h}$ post-infection in SDS loading buffer and $\mathrm{Rb}$ (top) and p107 (bottom) proteins were detected by western blotting using anti-Rb monoclonal antibody 14001A (Pharmigen) and anti-p107 rabbit polyclonal antibody SC318 (Santa Cruz Biotechnology) as described ${ }^{24}$. d. Coexpression of Ras and Myc does not affect the activity of either protein. Cells were collected $30 \mathrm{~h}$ post-infection in SDS loading buffer and Erk 1 and Erk2 were detected by western blotting using an anti-Erk1 monoclonal antibody (which cross-reacts with Erk2) M12320 (top) (Transduction Laboratories) or with a phospho-specific rabbit polyclonal anti-Erk1/2 antibody 9101A (middle) (New England Biolabs). The phosphorylated forms of Erk1 and Erk2 represent the upper band of each doublet; the Erk1 protein in the Con + serum sample is present but it is underrepresented in this sample. Cdc25A protein was detected by western blotting using rabbit polyclonal anti-cdc25A antibody SC-97 (bottom) (Santa Cruz Biotechnology). e, Myc activates the expression of the E2F1 gene. Cells treated as in a were collected after $15 \mathrm{~h}$ infection and processed for northern analysis using specific probes for E2F1 and GAPDH.

Figure 4 Expression of Myc and Ras leads to a loss of the p27 cyclin-dependent kinase inhibitor. REF52 cells were plated, starved and infected with the indicated viruses as in Fig. 3. Cells were either collected in SDS loading buffer at $30 \mathrm{~h}$ post-infection and p27 protein was detected by western blotting using rabbit polyclonal anti-p27 antibody SC-528 (Santa Cruz) (top row) or collected and processed for northern analysis using specific probes for p27 and GAPDH mRNAs (middle and bottom rows). 